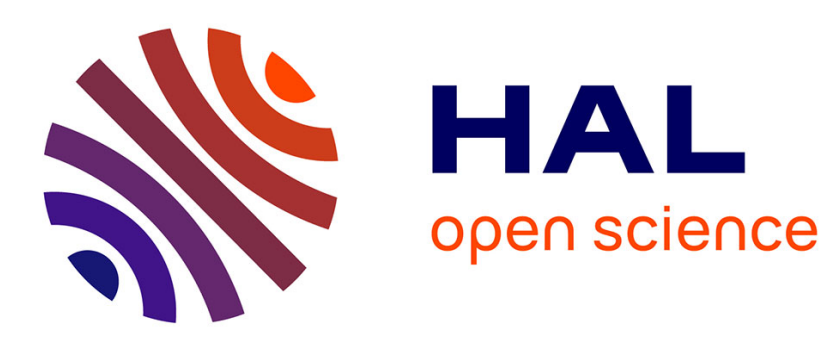

\title{
Can writing a new word detract from learning it? More negative effects of forced output during vocabulary learning
}

\author{
Joe Barcroft
}

\section{- To cite this version:}

Joe Barcroft. Can writing a new word detract from learning it? More negative effects of forced output during vocabulary learning. Second Language Research, 2006, 22 (4), pp.487-497. 10.1191/0267658306sr276oa . hal-00572107

\section{HAL Id: hal-00572107 \\ https://hal.science/hal-00572107}

Submitted on 1 Mar 2011

HAL is a multi-disciplinary open access archive for the deposit and dissemination of scientific research documents, whether they are published or not. The documents may come from teaching and research institutions in France or abroad, or from public or private research centers.
L'archive ouverte pluridisciplinaire HAL, est destinée au dépôt et à la diffusion de documents scientifiques de niveau recherche, publiés ou non, émanant des établissements d'enseignement et de recherche français ou étrangers, des laboratoires publics ou privés. 


\section{Can writing a new word detract from learning it? More negative effects of forced output during vocabulary learning}

Joe Barcroft Washington University in St Louis

Received July 2004; revised June 2005; accepted July 2005

This study examined effects of word writing on second language vocabulary learning. In two experiments, English-speaking learners of Spanish attempted to learn 24 Spanish nouns while viewing word-picture pairs. The participants copied 12 target words and wrote nothing for the other 12 target words being studied. Productive vocabulary learning on immediate and delayed ( 2 days later) measures was higher in the no-writing condition. These findings suggest that this type of forced output without access to meaning can detract from word learning by exhausting processing resources needed to encode novel lexical forms.

\section{Introduction}

In evaluating the role of output (language produced by a learner) in second language (L2) acquisition, we may distinguish between output with access and output without access to meaning. Output with access refers to 'activating the lexical items and grammatical forms necessary to express particular meanings' (VanPatten, 2003: 63). Output without access, on the other hand, involves language production that does not require this type of activation, such as when a learner simply repeats something without intending to convey meaning. This study assessed the effects of copying target words (word writing) on L2 vocabulary

Address for correspondence: Joe Barcroft, Department of Romance Languages and Literature, Washington University in St Louis, Campus Box 1077, One Brookings Drive, St Louis, MO 63130-4899, USA; e-mail: barcroft@wustl.edu 
learning. Word writing does not require access to meaning. From an input processing perspective, therefore, this type of output may decrease new word learning by exhausting cognitive processing resources that could be used to encode new word forms and establish new form-meaning mappings. This resource depletion for output (without access) hypothesis would gain support if word writing was found to produce less vocabulary learning than alternative no-writing conditions.

\section{Previous research on sentence writing, word writing and vocabulary learning}

Previous studies have assessed effects of writing target words in sentences (sentence writing) and word writing on different measures of vocabulary learning. Both sentence writing and word writing involve output, but sentence writing involves tasks beyond word writing, such as elaborating on the meaning of target words, writing other words in each sentence, and processing for syntax. Previous studies have led to mixed conclusions about the effects of sentence writing. Some researchers found writing target words in sentences (Coomber et al., 1986) or essays (Laufer, 1997) to be more effective than alternative techniques. Others have found sentence writing to produce no effect (L1 study: Pressley et al., 1982) or negative effects (L1 studies: Pressley et al., 1982; McDaniel \& Kearney, 1984; L2 studies: Barcroft, 1998; 2000; 2004; Folse, 1999) relative to alternative methods. Barcroft (2000; 2002; 2004) has maintained that these mixed findings may be attributed to particular operationalizations of 'deeper processing' in competing conditions, use of receptive versus productive measures, and other methodological limitations. Taking these considerations into account, the overall pattern of findings suggests that requiring learners to write target words in sentences can decrease their ability to learn those words by depleting processing resources that otherwise could be used to encode target word forms and establish form-meaning connections.

Research on word writing and L2 vocabulary learning has been limited. According to the resource depletion for output (RDO) hypothesis, copying a target word may exhaust processing resources that otherwise could be directed toward encoding the target word form and 
establishing new form-meaning mappings. The hypothesis does not exclude the possibility that producing a word to convey meaning may facilitate vocabulary learning. Self-generation of a target word presupposes prior exposure and input processing of the word, and studies have demonstrated positive effects for self-generation of target words on L2 vocabulary learning (Royer, 1973; McNamara and Healy, 1995). What remains in question is the effect of simply copying target words, a form of output without access. The RDO hypothesis predicts negative effects for this type of output.

Thomas and Dieter (1987) conducted a study on word writing among English-speaking learners of L2 French. The results of their first experiment indicated that word writing positively affected performance on an English-to-French translation task using scoring based on complete words (W) and complete words plus words with one letter wrong $(\mathrm{W}+(\mathrm{W}-1))$ but not based on scoring that included word fragments $(\mathrm{W}+(\mathrm{W}-1)+\mathrm{F})$. The results of their second experiment revealed no significant differences using L2-to-L1 translation as a dependent measure. The results of their third experiment indicated higher free $\mathrm{L} 2$ recall in the writing group using $\mathrm{W}$ and $\mathrm{W}+(\mathrm{W}-1)$ scoring but not $\mathrm{W}+(\mathrm{W}-1)+\mathrm{F}$ scoring. The researchers interpreted these results from the perspective that word writing facilitated learning complete orthographic representations.

\section{The present study}

The present study consisted of two experiments on the effects of word writing on productive L2 vocabulary learning. These experiments differed from those of Thomas and Dieter in that they included:

- a within-subjects design;

- a different presentation pattern during the learning phase (fewer repetitions);

- more proficient learners; and

- a different scoring protocol, designed to be highly sensitive to both full and partial productive word knowledge.

The present experiments approximated the experimental paradigm used by Barcroft $(1998 ; 2000 ; 2004)$ in studies showing negative effects for 
sentence writing. When examined within this same type of experimental paradigm, what would be the effect (if any) of word writing?

\section{Experiment 1}

Experiment 1 assessed the effects of word writing during word-picture vocabulary learning using both immediate and delayed post-tests. If the results revealed a positive effect for word writing, they would provide evidence against the RDO hypothesis. If the results revealed a negative effect for word writing, they would provide evidence in favor of the RDO hypothesis.

a Method: Participants were 20 English-speaking L2 Spanish students in two second-semester Spanish classes at a large public university in the Midwestern United States. All participants met the following criteria:

- Their L1 was English.

- Spanish was not spoken regularly in their household.

- They did not correctly translate any of the target words on the pre-test.

Each participant attempted to learn 12 words in the word-writing condition and 12 words in the no-writing condition. To counterbalance learning conditions with word groups, 10 participants (Class 1) attempted to learn Words 1-12 in the no-writing condition and Words 13-24 in the word-writing condition, whereas the other 10 participants (Class 2) attempted to learn Words 1-12 in the word-writing condition and Words 13-24 in the word-writing condition.

The experiment included:

- a pre-test on which the 24 words appeared in reverse order from that of the learning phase (to avoid habituation while maintaining a structured order for counterbalancing);

- a language background questionnaire;

- a page with general instructions for the experiment;

- 24 numbered flash cards with each word written below its picture (for the learning phase); and 24 numbered flash cards with numbered pictures only (for testing); 
- an audiotape with prerecorded beeps for presenting the stimuli in a time-controlled manner; overhead projectors on which the flashcards were placed so that they would appear on a television screen;

- a word-writing sheet with instructions for the word-writing task and numbered boxes in which to write the words; and

- two post-tests with instructions and 24 numbered spaces.

The 24 experimental words were the same concrete nouns as those used in sentence writing studies by Barcroft $(1998 ; 2000 ; 2004)$ (e.g. serrote 'saw', regadera 'watering can', borla 'tassel'). Each of the two word groups contained 12 words. The average number of syllables in each word group was equal ( $M=3$ for both word groups). The average number of letters in each word group was approximately equal ( $M=7.42$ for Words $1-12, M=6.67$ for Words 13-24). The 24 pictures of the target words were black-and-white drawings.

Data were collected in the participants' classrooms during class hours based on the following procedures. Each participant completed a language background questionnaire and the pre-test. Each participant read general instructions and was forewarned that in the testing phase they would be asked to write the target words in Spanish. Each word was presented twice for 6 seconds each time. Words 1-12 were presented twice. Words 13-24 were then presented in the same manner. In the word writing condition, participants were instructed to write each word once in the appropriate numbered box on the sheet. Immediately after the learning phase, Post-test 1 was administered. Participants were to write the target Spanish words as pictures only appeared on the screen. The same 24 pictures from the learning phase were presented for 12 seconds each in the same order as in the learning phase. After Post-test 1, the researcher did not inform the participants about a subsequent post-test. Two days later, the researcher returned to administer Post-test 2, which was the same as Post-test 1 except that it was labeled Post-test 2. After Post-test 2, the participants were asked to write whether they practiced or had any additional contact with the 24 Spanish words. If any participant indicated having practiced the target words beyond only 'thinking about them', their Post-test 2 scores were excluded from the dataset.

Barcroft's (2000) lexical production scoring protocol (LPSP-written) was used to score both post-tests. A trained independent evaluator 
scored all post-tests. Blind scoring was used. LPSP-written scores reflect production of both fully and partially produced words (for details, see Barcroft, 2000; 2004). In an effort to represent each participant's knowledge of target word forms as accurately as possible, some target words were scored in intended spaces when participants indicated with arrows that they had misplaced a response or series of responses or when it was judged to be the case based on response patterns on both post-tests during blind scoring. Scores for Words 1-12 and Words 13-24 were tabulated, providing totals for the no-writing and wordwriting conditions. Two subjects from Class 2 were not present for Post-test 2 . The data provided by these participants and two randomly selected participants from Class 1 were excluded in order to maintain equal sizes at both post-tests.

$b$ Results: LPSP-written scores were submitted to an analysis of variance (ANOVA). Condition (no writing, word writing) and time (immediate, 2 days later) were within-subject independent variables. The dependent variable was score. Alpha was set at 0.05 for the statistical analyses. Means for condition over time appear in Table 1. Results of the ANOVA revealed significant main effects for condition, $F(1,15)=9.06, p=0.009, \quad \eta^{2}=0.377$, and for time, $F(1,15)=31.78, p<0.001, \eta^{2}=0.679$. No other significant main effects or interactions were revealed. Consistent with the RDO hypothesis, the results indicated that word writing had a negative effect on productive L2 vocabulary learning. This negative effect maintained over time.

Table 1 Experiment 1: means for condition over time

\begin{tabular}{llll}
\hline Time & Condition* & Mean & $S D$ \\
\hline Immediate & No writing & 5.75 & 2.16 \\
& Word writing & 4.30 & 2.54 \\
2 days later & No writing & 4.16 & 2.80 \\
& Word writing & 3.13 & 2.78 \\
Overall & No writing & 4.95 & 2.41 \\
& Word writing & 3.71 & 2.61 \\
\hline
\end{tabular}

Note: ${ }^{*} n=16$ for each condition. 


\section{Experiment 2}

Experiment 2 was a partial replication of Experiment 1 with a larger sample, participants from a different university, presentation of stimuli using a computer-based presentation program, and provisions for the participants to cover words that they had written previously during the learning phase (using a piece of construction paper). This final provision was included to control for the possibility that the appearance of the previously written words within the participants' field of vision in Experiment 1 might have caused confusion between different target word forms and referents. Additionally, during the testing phase of Experiment 2, the order of two consecutive target words (18. as a 'handle' and 19. sacudidor 'feather duster') was reversed from the order in which those two words appeared during the learning phase. This difference was consistent across both learning conditions. The extent to which the participants did or did not invert those two particular words on their post-tests was analysed to explore the extent to which the participants' performance on the post-tests reflected learning formmeaning connections between the target words and their referents as opposed to learning a particular presentation order. Other differences in Experiment 2 are described in the following sections.

a Method: Forty-six Spanish students in four second-semester Spanish classes at a private university in the Midwestern United States participated. All met the same criteria as in Experiment 1. The experimental materials in Experiment 2 were similar to those in Experiment 1, except that a computer presentation program was used to present instructions and the stimuli. The experimental words were the same as in Experiment 1. Data collection procedures followed those of Experiment 1 except that for the writing condition the participants were provided with sheets of construction paper to cover all previously written words on their word-writing sheets. Scoring procedures were the same as those used in Experiment 1.

b Results: The data were analysed as in Experiment 1, except for one additional analysis. Cases in which participants did or did not invert the consecutive target words asa 'handle' and sacudidor 'feather duster' were noted, totaled, and reported as results. Means for condition over 
Table 2 Experiment 2: means for condition over time

\begin{tabular}{llll}
\hline Time & Condition* & Mean & $S D$ \\
\hline Immediate & No writing & 6.50 & 2.30 \\
& Word writing & 5.48 & 2.35 \\
2 days later & No writing & 5.04 & 2.39 \\
& Word writing & 4.05 & 2.29 \\
Overall & No writing & 5.77 & 2.29 \\
& Word writing & 4.77 & 2.22 \\
\hline
\end{tabular}

Note: ${ }^{*} n=46$ for each condition.

time appear in Table 2. Results of the ANOVA revealed significant main effects for condition, $F(1,45)=10.43, p=0.002, \eta^{2}=0.188$, and for time, $F(1,45)=99.80, p<0.001, \eta^{2}=0.689$. No other significant main effects or interactions emerged. Consistent with RDO hypothesis, the results of Experiment 2 indicated that word writing had a negative effect on productive L2 vocabulary learning. This negative effect was maintained over time.

Additionally, based on data provided by the 46 participants, responses for the target words asa 'handle' and sacudidor 'feather duster' were given 44 times on Post-test 1 and 39 times on Post-test 2. Of these 83 responses, none included an incorrect inversion of the target words back to the order in which the words had appeared in the learning phase, suggesting that these results reflect vocabulary learning beyond learning of a single presentation order.

\section{Discussion}

The findings of both experiments indicate that copying target words negatively affected productive L2 vocabulary learning. This section discusses the implications of these findings with regard to research on sentence writing and vocabulary, the resource depletion for output hypothesis, and the effects of word writing in different types of experimental paradigms.

Previous studies on sentence writing and L2 vocabulary learning found that requiring learners to write new words in sentences had strong negative effects on productive word gain. Barcroft (1998; 2000; 2004) found decreases in the area of $100 \%$ for sentence writing as compared to no sentence writing. In the present study, word-writing scores were 
approximately 0.34 times lower (Experiment 1) and 0.21 times lower (Experiment 2) than no-writing scores. These numbers suggest that some, but not all, of the negative effect of sentence writing may be attributed to the act of copying target words. Semantic evaluation and other subtasks in sentence writing remain as other probable contributors to the large negative effect of sentence writing.

The present findings are consistent with the resource depletion for output (RDO) hypothesis because they suggest that forcing learners to produce output without access can detract from learning new L2 words. If one considers the role of processing resource allocation in vocabulary learning, the predictions of RDO and the findings of the present study are not counter-intuitive. In order to learn a new word, one must allocate sufficient processing resources toward encoding the target word form, isolating an appropriate semantic representation, and mapping word form onto the semantic representation. In a sufficiently demanding vocabulary learning task, forced output without access can exhaust processing resources that could otherwise be directed toward encoding the word forms and developing form-meaning mappings. The RDO hypothesis and the present findings are also consistent with theoretical accounts that emphasize specificity of processing type, such as transfer-appropriate processing (Morris et al., 1977) and the type of processing - resource allocation model (Barcroft, 2000; 2002) for lexical acquisition. From these perspectives, the sub-tasks involved word writing (e.g. motor activity, looking away from words on the screen) did not invoke the correct component processes needed for most effective vocabulary learning.

The combined findings of Thomas and Dieter (1987) and the present study also suggest that the effects of word writing may depend upon experimental paradigm and methodology. Whereas Thomas and Dieter found positive effects for word writing on some measures and null effects on others, the present study revealed negative effects for word writing using LPSP-written scoring. How can the difference in results between the two studies be explained?

Three potentially critical differences between the present study and Thomas and Dieter's (1987) study concern task difficulty, presentation format, and scoring. First, more target words were used in Thomas and Dieter's study, but the inclusion of an additional repetition for each word and an additional 4 seconds for every repetition may have resulted in a less 
demanding vocabulary learning task than that of the present study. If so, the negative effect of word writing via processing resource depletion may have been less detectable. Second, Thomas and Dieter presented target words both visually and orally. As such, word writing may have enabled participants to attend to sound-to-spelling correspondences in a manner that was more beneficial to encoding the new forms. Third, Thomas and Dieter's scoring method most sensitive to partial word form knowledge (most inclusion of partial word fragments) did not yield positive effects. In the present study, negative effects were obtained using LPSP-written scoring, which is very sensitive to partial word knowledge. Therefore, the potentially negative effects of word writing may be more detectable with measures that are more sensitive to partial word form knowledge.

\section{Future research}

Additional research may help to explain the combined findings of Thomas and Dieter and the present study by manipulating factors such as the difficulty of the vocabulary learning task and the nature of the word-writing task. Future studies also may explore how alternative types of output affect vocabulary learning and other aspects of language learning. The present study demonstrated that forced output in the form of word writing detracted from L2 vocabulary learning in the context of a relatively demanding vocabulary learning task. From the perspective of processing resource allocation, forced output of this nature did not activate component processes needed for effective vocabulary learning but, instead, exhausted processing resources needed to encode new word forms and make form-meaning mappings. What other types of output might affect L2 vocabulary learning in this manner? Do these types of output affect other areas of L2 learning such as phonology and grammar in the same manner? Future research on these questions should help to advance our understanding of the impact of different types of output on L2 acquisition.

\section{References}

Barcroft, J. 1998: L2 vocabulary learning: do sentence writing and oral repetition help? Poster Presentation at the Second Language Research Forum, Honolulu, HI. 
- 2000: The Effects of sentence writing as semantic elaboration on the allocation of processing resources and second language lexical acquisition. Unpublished doctoral dissertation, University of Illinois at UrbanaChampaign.

2002: Semantic and structural elaboration in L2 lexical acquisition. Language Learning 52, 323-63.

- 2004 Effects of sentence writing in L2 lexical acquisition. Second Language Research 20, 303-34.

Coomber, J.E., Ramstad, D.A. and Sheets, D.R. 1986: Elaboration in vocabulary learning: A comparison of three rehearsal methods. Research in the Teaching of English 20, 281-93.

Folse, K.S. 1999: The effect of type of written practice activity on second language vocabulary retention. Unpublished doctoral dissertation, University of South Florida.

Laufer, B. 1997: Incidental vocabulary acquisition: In praise of output. Unpublished paper presented at the Second Language Research Forum, East Lansing, MI.

McDaniel, M.A. and Kearney, E.M. 1984: Optimal learning strategies and their spontaneous use: The importance of task-appropriate processing. Memory and Cognition 12, 361-73.

McNamara, D.S. and Healy, A.F. 1995: A generation advantage for multiplication skill training and nonword vocabulary acquisition. In Healy, A.F. and Bourne Jr., L.E., editors, Learning and memory of knowledge and skills: durability and specificity, 132-69. Sage.

Morris, C.D., Bransford, J.D. and Franks, J.J. 1977: Levels of processing versus transfer appropriate processing. Journal of Verbal Learning and Verbal Behavior 16, 519-33.

Pressley, M., Levin, J.R. and Miller, G.E. 1982: The keyword method compared to alternative vocabulary-learning strategies. Contemporary Educational Psychology 7, 50-60.

Royer, J.M. 1973: Memory effects for test-like events during acquisition of foreign language vocabulary. Psychological Reports 32, 195-98.

Thomas, M.H. and Dieter, J.N. 1987: The positive effects of writing practice on integration of foreign words in memory. Journal of Educational Psychology 79, 249-53.

VanPatten, B. 2003: From input to output: A teacher's guide to second language acquisition. McGraw-Hill. 